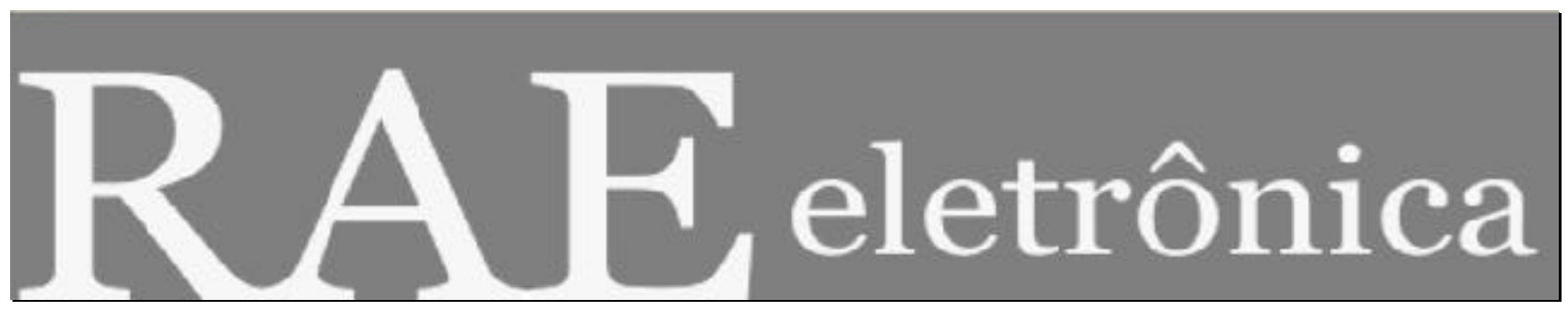

\title{
REDES E ALIANÇAS ESTRATÉGICAS NO BRASIL: CASO CVRD
}

Por:

\section{Tatiana L. Tauhata}

T. Diana L. v. A. de Macedo-Soares

RAE-eletrônica, v. 3, n. 1, Art. 4, jan./jun. 2004

http://www.rae.com.br/eletronica/index.cfm?FuseAction=Artigo\&ID=1811\&Secao=ESTRATÉGIA\& Volume $=3 \&$ Numero $=1 \& A$ no $=2004$

CCopyright, 2004, RAE-eletrônica. Todos os direitos, inclusive de tradução, são reservados. É permitido citar parte de artigos sem autorização prévia desde que seja identificada a fonte. A reprodução total de artigos é proibida. Os artigos só devem ser usados para uso pessoal e nãocomercial. Em caso de dúvidas, consulte a redação: redacao@rae.com.br.

A RAE-eletrônica é a revista on-line da FGV-EAESP, totalmente aberta e criada com o objetivo de agilizar a veiculação de trabalhos inéditos. Lançada em janeiro de 2002, com perfil acadêmico, é dedicada a professores, pesquisadores e estudantes. Para mais informações consulte o site www.rae.com.br/eletronica.

RAE-eletrônica

ISSN 1676-5648

(C2004 Editora: Fundação Getulio Vargas - Escola de Administração de Empresas de São Paulo

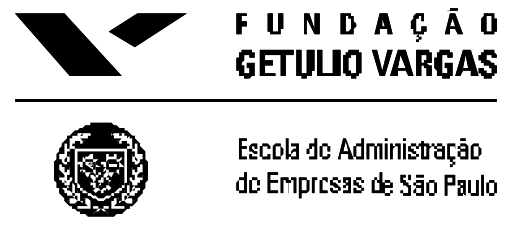




\title{
REDES E ALIANÇAS ESTRATÉGICAS NO BRASIL: CASO CVRD
}

\section{RESUMO}

No cenário atual de competição, as empresas têm estabelecido um número crescente de alianças e redes para complementar seus recursos, reduzir incertezas e sustentar sua vantagem competitiva. Este artigo pretende evidenciar a importância de levar em conta na gestão estratégica de empresas que atuam em redes de alianças as implicações destas redes para sua conduta e desempenho. Tem foco na maior exportadora brasileira que é líder mundial da indústria de minério de ferro - a Cia Vale do Rio Doce usando uma metodologia de estudo de caso e um novo ferramental de análise estratégica sob a perspectiva relacional. Com base em pesquisa bibliográfica, documental e de campo, mostra que esta perspectiva pode trazer novos subsídios valiosos para o planejamento estratégico da empresa, ao revelar implicações, em termos de oportunidades, ameaças, forças e fraquezas das características das suas redes, que atenuam, neutralizam ou exacerbam àquelas identificadas por análises estratégicas tradicionais.

\begin{abstract}
In the current highly competitive scenario, firms are increasingly establishing alliances and integrating networks to complement their resources, reduce uncertainties and sustain their competitiveness. This paper aims at highlighting the importance of taking into account in the management of firms embedded in strategic networks, the latter's implications for firm conduct and performance. It focusses on a Brazilian company that is the leader in the iron ore business - Cia Vale do Rio Doce - using case study methodology and new conceptual tools for strategic assessment from a relational perspective. Based on bibliographic, documental and empirical research, it shows how this perspective can provide new valuable insights for the strategic planning of the firm by revealing network implications, in terms of opportunities, threats, strengths and weaknesses, that reduce, neutralize or increase those identified by way of traditional strategic analyses.
\end{abstract}

\section{PALAVRAS-CHAVE}

Alianças estratégicas; redes estratégicas; gestão estratégica; adequação estratégica; implicações estratégicas.

\section{KEY-WORDS}

Strategic Alliances, strategic networks, strategic management, strategic fit, strategic implications. 


\section{INTRODUÇÃO}

No cenário empresarial atual de mudança e complexidade crescentes, a imagem de empresas isoladas competindo no mercado de forma atomística não é mais adequada (Gulati, Nohria \& Zaheer, 2000). Para sustentar sua vantagem competitiva, um número crescente de empresas no Brasil, como no resto do mundo, está estabelecendo múltiplas alianças de diferentes tipos, constituindo-se em redes, inclusive virtuais (Pitassi \& Macedo-Soares, 2002). Em particular no ambiente global, a busca da competitividade das empresas se reforça sob esta perspectiva, onde é absolutamente decisivo o papel e a importância das relações e redes inter-firmas que atravessam fronteiras das indústrias e países.

Também na área acadêmica, tem havido inúmeras pesquisas relacionadas ao estabelecimento de relacionamentos estratégicos, tais como joint ventures e outros tipos de alianças, bem como redes de relacionamento. Estas configurações em redes são cada vez mais importantes e críticas para o desempenho e a conduta das empresas na maioria das indústrias (Gulati et al., 2000). Consequentemente, os modelos tradicionais de competição que analisam apenas a estrutura da indústria e os recursos da empresa e não levam em conta a formação e a dinâmica das redes são insuficientes para explicar adequadamente o desempenho das empresas que atuam em redes, ou para auxiliar a formulação e implementação de novas estratégias. Entretanto, as suas implicações estratégicas têm sido não somente pouco investigadas, mas também pouco consideradas no planejamento das empresas.

No caso do Brasil, Tavares (2002) constatou que dois terços das maiores empresas líderes (67\%) estabelecem alianças estratégicas principalmente buscando o compartilhamento de recursos / competências complementares e a redução de custos. Sua pesquisa revelou também que já um terço das maiores empresas líderes no país atua em redes estratégicas, sendo que a grande maioria percebe que estas influenciam seu desempenho e mudam a natureza da competição.

Este fenômeno não é exclusivo das grandes empresas no Brasil. Em pesquisa recente da Deloitte (2002) as alianças estratégicas foram apontadas como um dos fatores mais críticos para o crescimento das pequenas e médias empresas que operam no Brasil.

Até mesmo na indústria de minério de ferro e na siderurgia, setores tradicionais e intimamente relacionados, modificações estruturais têm ocorrido no sentido de estreitar as relações entre os vários atores mediante a formação de alianças e redes organizacionais, principalmente envolvendo fornecedores e clientes e, em certos casos, até mesmo concorrentes.

A indústria siderúrgica é marcada pela consolidação, reestruturação e internacionalização dos produtores, incluindo uma série de fusões, aquisições, restruturações e formação de alianças e blocos estratégicos envolvendo os principais participantes do setor, que extrapolam as dimensões nacional e regional, principalmente na Europa Ocidental e na Ásia (De Paula 2000b). No caso americano, por exemplo, a colaboração entre empresas do setor é motivada pela necessidade de recursos ou de sua utilização, que extrapola as fronteiras da empresa (Ojode 2000). Recentemente, a indústria de minério de ferro vem também passando por um intenso processo de consolidação, ampliando a pressão sobre as siderúrgicas, levando a participação das três maiores empresas no comércio transoceânico de minério de ferro (CVRD, Rio Tinto e BHP-Billiton) de 47,5\% em 1996 para 71,4\% em 2000 (De Paula, 2000a). Por outro lado, apresenta alianças com parceiros na siderurgia visando aprofundamento de relacionamentos comerciais, desenvolvimento de projetos e tecnologias (Tex Report 2002a; Tex Report 2002b, Neves 2001).

Neste trabalho avaliaram se os impactos de redes / alianças na gestão estratégica da unidade de 
Minério de Ferro da Cia Vale do Rio Doce (CVRD-UMF). Apesar de ser um dos principais grupos empresariais brasileiros e uma das maiores empresas mineradoras do mundo, ela se encontra em situação de desafio para sustentar sua vantagem competitiva. Este desafio consiste na implementação de sua estratégia de orientação ao cliente num cenário de consolidação e fortalecimento de seu cliente a indústria siderúrgica. Neste contexto, um dos componentes fundamentais para atender o cliente de forma mais completa tem sido o estabelecimento de alianças e redes, visando o aprofundamento do relacionamento com seus clientes e fortalecimento de suas relações comerciais. Por ser uma empresa líder, com desempenho competitivo por padrões internacionais, e uma pioneira em termos da atuação em redes / alianças, a CVRD pode servir de exemplo para outras empresas no Brasil e no mundo, trazendo lições pertinentes a essa atuação para o ambiente empresarial.

O objetivo deste artigo é de compartilhar algumas destas lições mostrando a importância crítica para a tomada de decisão e o planejamento estratégico, no caso de uma empresa que atua em alianças e redes, de levar em conta as implicações para sua conduta e desempenho, não somente de fatores organizacionais e macroambientais, mas, também, das características das suas redes e alianças.

Este artigo está dividido em quatro partes. Nas primeiras duas, explicam-se o referencial teórico e os métodos da pesquisa. Na terceira parte, apresentamse seus principais resultados, que são então discutidos em termos da contribuição das alianças e redes para o planejamento estratégico da empresa, evidenciando sua relevância. Na última parte, formulamse algumas conclusões e sugestões para futuras pesquisas. O conteúdo deste artigo é de inteira responsabilidade dos seus autores.

\section{REFERENCIAL TEÓRICO -FERRAMENTAL PARA ANÁLISE RELACIONAL}

Para a investigação dos impactos de redes/alianças na gestão estratégica da CVRD-UMF foi utilizado um ferramental para avaliação de adequação estratégica de empresas que atuam em redes, descrito nesta seção - que contém transcrições do trabalho de Macedo-Soares \& Tauhata (2002) em que foram apresentados os resultados preliminares de seu teste piloto. Este ferramental inclui três componentes: 1) uma metodologia para realizar avaliações de adequação estratégica na ótica relacional, ou seja, considerando as implicações estratégicas das características das redes / alianças; 2) um conjunto de construtos e indicadores relacionais para capturar e analisar os dados necessários à avaliação em questão; 3) um modelo conceitual para auxiliar o mapeamento e a análise da rede estratégica da empresa específica e dos fatores pertinentes (SNA - Strategic Network Analysis Model).

Embora existam na literatura alguns outros arcabouços para auxiliar a análise dos impactos das redes de relacionamentos estratégicos na competitividade da empresa (Contractor, Wasserman \& Faust, 2000; Gnyawali \& Madha van, 2001), o ferramental acima mencionado foi considerado mais adequado ao estudo porquanto permite considerar os fatores relacionais em conjunção com os outros fatores estrategicamente significativos - organizacionais, estruturais da indústria e macroambientais - dentro de uma perspectiva holística e dinâmica. Tem ainda a vantagem de poder complementar análises tradicionais do tipo "SWOT" ("forças, fraquezas, oportunidades, ameaças"). Este tipo de complementação torna-se tanto mais fácil que o ferramental comporta construtos pertinentes às óticas tradicional e relacional, o que não é o caso nos arcabouços propostos na literatura revisada.

Argumenta-se aqui que a "ótica tradicional" pode ser insuficiente para o planejamento estratégico de empresas que atuam em alianças e redes. Conforme observado por Dyer \& Singh (1998), que enfatizam a importância de adotar uma "ótica relacional", os recursos críticos de uma empresa podem estar além de suas fronteiras nos próprios relacionamentos que contribuem assim à sua vantagem 
competitiva sustentável.

Cabe notar que pelo termo "ótica tradicional" entende-se uma abordagem que leve em conta como variáveis estrategicamente significativas apenas os fatores organizacionais - caso da "resource based view" - RBV (Barney, 1991; Rumelt, 1984; Wernerfelt, 1984), ou os fatores estruturais da indústria e macroambientais -escola posicionamento (Porter, 1980, Austin, 1990), ou mesmo a conjunção destes - caso das abordagens integrativas (Collis \& Montgomery, 1998,), sem contemplar os fatores relacionais.

Incorporando-se a perspectiva relacional, pode-se derivar uma visão mais abrangente do comportamento estratégico das empresas. Fornece maiores insights quanto às fontes de vantagem competitiva e criação de recursos valiosos e inimitáveis presentes fora das fronteiras da empresa, e um entendimento mais refinado da estrutura da indústria em que ela se situa. Permite perceber as oportunidades e restrições criadas pelas redes estratégicas, que podem proporcionar às empresas acesso a informações, recursos, mercados e tecnologias que contribuem para a vantagem competitiva, bem como compartilhamento de riscos, outsourcing de cadeias de valor e funções organizacionais, ao mesmo tempo em que podem encapsular as empresas em relações improdutivas ou privá-las de outras associações mais vantajosas (Gulati et al., 2000).

\section{Metodologia para Avaliação de Adequação Estratégica}

Na pesquisa partiu-se da premissa que a análise estratégica implica avaliações com base no princípio clássico de adequação estratégica: a importância para a efetividade da estratégia de garantir consistência entre todos os fatores estrategicamente significativos (Hofer \& Schendel, 1978). Na perspectiva integrativa de Macedo-Soares (2002), esses fatores devem incluir também variáveis relacionais, ou seja, "a estratégia só pode ser considerada adequada quando capitaliza as forças constituídas, não somente pelos recursos internos da empresa e pelas condições organizacionais necessárias para alavancá-los, mas, também, pelos recursos proporcionados pela rede de relacionamentos, reduzindo as fraquezas da empresa e de sua rede. O objetivo é de explorar, tanto as oportunidades oriundas do macro-ambiente, quanto aquelas criadas pela rede, minimizando eventuais ameaças" (p. 294).

Adaptourse aqui à ótica relacional o conceito de "boa" (adequada) estratégia de Barney (1996, p. 27) de acordo com a ótica tradicional. É preciso lembrar que para Barney uma "boa estratégia" é uma estratégia que torna a organização capaz de atingir seus objetivos ao neutralizar as ameaças e explorar as oportunidades enquanto capitaliza forças, atenuando fraquezas.

A metodologia adotada, restrita neste artigo à análise relacional, envolve os seguintes passos:

- Passo 1: caracterização da estratégia utilizando construtos de Fahey \& Randall (1998) para análise do conteúdo da estratégia - metas, escopo geográfico, de produto, vertical, de stakeholders (partes interessadas), atributos diferenciadores, estrutura de preço - e do seu processo - formulação e implementação, bem como a tipologia de Mintzberg (1988). Mintzberg propõe estratégias genéricas baseadas em duas dimensões: i) escopo (amplo ou estreito) de produtos e serviços, e ii) diferenciação desagregada nas seguintes categorias: qualidade, projeto, suporte, imagem, preço e não-diferenciação. Apesar de a tipologia de Porter (1980) ser mais utilizada, adotouse a de Mintzberg, pois seu maior poder descritivo a torna mais adequada ao complexo ambiente 
competitivo atual (Kotha \& Vadlamani, 1995);

- Passo 2: identificação e classificação das alianças que constituem a rede estratégica da empresa, chamada de "ego-rede". Redes são definidas aqui como "um conjunto de relacionamentos da empresa, tanto horizontais como verticais, com outras organizações incluindo relações que atravessam as fronteiras de indústrias e países; são compostas de laços interorganizacionais duradouros, de significado estratégico..." tais como alianças estratégicas (Gulati et al. 2000, p. 203). Estas são "arranjos voluntários entre empresas envolvendo troca, compartilhamento, ou codesenvolvimento de produtos, tecnologias ou serviços" (Gulati 1998, p. 293), que contribuem diretamente para a vantagem competitiva da empresa;

- Passo 3: identificação das características da rede estratégica e a análise das suas implicações nos níveis da empresa e da indústria, em termos de constituírem, respectivamente, forças e fraquezas, oportunidades e ameaças;

- Passo 4: avaliação da consistência dessas implicações com a estratégia da empresa de acordo com o conceito de adequação estratégica dinâmica (Zajac, Kraatz, \& Bresser 2000);

- Passo 5: definição de mudanças nos fatores relacionais ou organizacionais para melhorar ou criar as condições necessárias à adequação estratégica dinâmica;

- Passo 6: tomada de decisão estratégica - ajustes ou adoção de nova estratégia, considerando todos os stakeholders e a importância de sustentar um desempenho superior.

\section{Construtos Relacionais}

As listas de referência com os construtos para operacionalizar a análise estratégica pela ótica relacional são apresentadas em Macedo-Soares (2002) e foram baseadas principalmente nos trabalhos de Galaskiewicz \& Zaheer (1999), Gulati et al. (2000) e Knoke (2001).

- Galaskiewicz e Zaheer (1999) propuseram três dimensões chave e um conjunto de características das alianças e redes para analisar seu impacto no nível da empresa;

- Gulati et al. (2000) mostraram como estas características relacionais têm implicações tanto no nível da empresa, como forças ou fraquezas, quanto no nível da indústria em termos de oportunidades e ameaças, e sugerem implicitamente que a gestão da rede deve ser considerada como outra dimensão;

- Knoke (2001) contribuiu com conceitos valiosos para selecionar o nível apropriado para operacionalização da análise da rede estratégica: propõe o conceito de "rede egocêntrica" formada por uma amostra dos atores e seus laços diretos entre eles;

- Macedo-Soares (2002) reuniu na sua metodologia de análise estratégica todos estes conceitos e adaptou o conceito de Knoke (2001): em sua abordagem a "ego-rede" da empresa focal, isto é, a rede formada pelos atores estratégicos que compõem sua arena competitiva é mapeada e decomposta nas díades (alianças), suas características são classificadas de modo a auxiliar a 
Tatiana L. Tauhata - T. Diana L. v. A de Macedo-Soares

identificação das suas implicações, com vistas a realizar uma análise relacional do tipo "SWOT" no âmbito de uma avaliação de adequação estratégica abrangente.

Os construtos (negrito), subconstrutos (negrito itálico) e indicadores (ítalico) referentes às características das três dimensões da rede consideradas chaves são: 1) estrutura - padrão de relacionamentos, cujas implicações dependem da sua densidade (número de laços; alta/baixa) e coesão, em termos de ter laços diretos, indiretos, ou estruturalmente equivalentes (compartilhamento dos mesmos clientes ou mesmos tipos de laços), a centralidade da empresa na rede (sua participação em número significativo de relacionamentos), e a existência de orifícios estruturais quando parceiros estão conectados apenas por meio da empresa focal que pode explorar essa situação; 2) composição papel dos membros da rede, cujas implicações dependem do seu status, (riqueza em recursos/ competências no parceiro real ou potencial que a empresa focal percebe como valiosos, por vários motivos, como para complementar ou otimizar os seus. Os recursos podem ainda ser classificados quanto ao volume, tipo e qualidade.); e 3) modalidades - o tipo de regras/normas institucionais que governam o comportamento relacional da rede, contratos formais ou acordos informais, cujas implicações variam em acordo com o tipo / natureza de laço - colaborativo ou oportunista, forte ou fraco.

No nível da empresa, considera-se uma quarta dimensão: administração da rede - que envolve uso de mecanismos de governança, gerenciamento das alianças, gestão de mudanças da rede, administração das expectativas e conflitos dos parceiros (Dyer \& Singh 1998, Kale, Singh \& Perlmutter, 2000), experiência com alianças (Anand \& Khanna 2000), adequação dinâmica dos múltiplos parceiros em termos de compatibilidade de estratégias, culturas, estilos gerenciais, e de complementaridade de recursos (Douma, Bilderbeek, Idenburg \& Looise 2000), medição de desempenho, etc.

No nível da empresa, cada uma dessas características pode ser considerada uma força ou uma fraqueza. No nível da indústria, as implicações da rede se apresentam como oportunidades e ameaças (Gulati et al., 2000).

\section{Modelo de Análise de Redes Estratégicas}

O modelo SNA tem como função de ajudar a mapear as principais alianças e características relacionais da "ego-rede" da empresa, ou seja, a rede constituída pela empresa focal, por suas alianças estratégicas principais e pelos laços significativos entre seus parceiros. Consiste em uma evolução de um modelo genérico integrativo, que incorporava construtos de Austin (1990), de Porter (1980) e da escola "resource-based" - RBV (Wernerfelt, 1984) para realizar análises estratégicas na ótica tradicional (Macedo-Soares, 2002), ao incluir construtos pertinentes à análise relacional.

No modelo SNA, a forma da empresa focal (CVRD-UMF na Figura 1) sugere um sistema em equilíbrio quase perfeito, mas não perfeito, para propiciar a inovação na busca contínua do seu equilíbrio, enfatizando-se a importância desta para a adequação estratégica dinâmica. Os atores estratégicos são cobcados ao longo de uma elipse que configura as fronteiras pouco definidas da "rede de valor" da empresa. Inspira-se no conceito de "rede de valor" de Brandenburger \& Nalebuff (1997): uma rede que inclui todos os atores estratégicos - cliente, fornecedor, rival, novo entrante, substituto, "complementor" (complementador) - e suas interdependências como parceiro ou não, que influenciam a distribuição de poder entre eles e a empresa, e, conseqüentemente, seu potencial de agregar valor significativo para sua vantagem competitiva. 
$\mathrm{Na}$ terceira parte deste artigo, quando se apresentam os resultados da pesquisa, o modelo será ilustrado com sua aplicação na empresa objeto do estudo. Antes, cabe explicar os métodos adotados na pesquisa.

\section{METODOS DE PESQUISA}

\section{Métodos para o Estudo de Caso}

O "estudo de caso" foi considerado o meio mais adequado para a pesquisa na CVRD-UMF, pois se tratava de investigar em profundidade um fenômeno contemporâneo no seu contexto real (Yin 1994). Para tanto, adotourse a abordagem de Yin por se tratar de uma verdadeira estratégia de pesquisa abrangente no sentido de englobar várias técnicas diferentes de coleta e análise de dados. A proposta de Yin enfatiza a importância do uso de triangulação de métodos para conseguir dados de múltiplas fontes de modo a produzir conclusões mais consistentes.

Coletaram-se dados pelos seguintes meios: a)investigação documental/telematizada, b)levantamento das percepções dos executivos quanto às implicações estratégicas das redes, c)entrevistas com os principais dirigentes para aprofundar questões complexas relativas à gestão das alianças e redes, d)observação participante com funcionários por parte de um dos autores.

No caso do levantamento, o principal instrumento foi um questionário predominantemente estruturado, cuja validade foi assegurada por basearem-se em construtos previamente testados em outras pesquisas empíricas (veja seção 1.2.2.). Após teste preliminar de sua confiabilidade e fidedignidade em outra unidade da empresa, o questionário foi enviado a uma amostra da população da empresa, constituída por pessoas envolvidas direta ou indiretamente na tomada de decisão estratégica da unidade (vide Apêndice 1).

Os dados coletados foram tratados por métodos quantitativos - estatísticos simples (médias, desviopadrão, distribuições de frequência), no caso das respostas às perguntas fechadas, e por métodos qualitativos - técnicas de análise de conteúdo (Morse 1994, Weber 1990), no caso das respostas às perguntas abertas e das entrevistas.

Com o objetivo de atenuar as limitações dos métodos adotados, valeutse do cruzamento dos resultados dos diferentes meios e fontes utilizados para checar sua consistência.

\section{RESULTADOS}

Os resultados são apresentados a seguir, sob forma de respostas às questões recomendadas na metodologia adotada para realizar a análise de adequação estratégica na CVRD-UMF. Considerandose o objetivo deste artigo, foca-se apenas nos resultados pertinentes à análise sob a ótica relacional. No Apêndice 2, são apresentados alguns gráficos com estatísticas, a título de exemplificação apenas, em função da grande quantidade de dados levantados. Para um maior detalhamento, vide Tauhata (2002).

Criada em 1942, a CVRD transformouse na maior empresa produtora e exportadora de minério de ferro e pelotas do mundo, e na maior exportadora do Brasil. Além do minério de ferro, atua em logística, energia, caulim, ouro e outros minerais, sendo a maior mineradora das Américas (dados da 
Bloomberg), com ações negociadas nas bolsas brasileira, americana e européia. A despeito do cenário internacional fortemente adverso, tem apresentado recordes de desempenho nos últimos anos - lucro líquido de $\mathrm{R} \$ 3,0$ bilhões em 2001 e $\mathrm{R} \$ \$ 2,0$ bilhões em 2002 - gerando consistentemente retornos para os acionistas bem superiores à média da indústria. Com um faturamento consolidado de $\mathrm{R} \$ 15,0$ bilhões (em 2002), apresenta forte capacidade de geração de caixa, sendo que a área de ferrosos representa cerca de $70 \%$ de seu EBITDA. Para sustentar seu desempenho, reavalia regularmente suas estratégias, em especial a do minério de ferro. A primeira pergunta da metodologia está diretamente relacionada às diretrizes estratégicas:

\section{Qual é a Estratégia da Unidade de Negócios de Minério de Ferro da CVRD (CVRD-UMF)?}

De acordo com a pesquisa documental, a estratégia da CVRD-UMF é de diferenciação, principalmente por qualidade, mas também por suporte, pois se propõe a entregar maior confiabilidade e desempenho por um produto com preço comparável aos concorrentes para satisfazer seus clientes. Seu escopo de produto é o minério de ferro, nas suas diversas formas, destinado à indústria siderúrgica. Seu escopo geográfico é global, com clientes principalmente na Ásia e na Europa e, em termos de verticais, compreende dois sistemas produtivos integrados mina-ferrovia-porto, usinas de pelotização, uma empresa de navegação e participações em siderúrgicas. Quanto aos stakeholders, é uma empresa aberta e seus principais controladores são grupos financeiros com influência política local relevante. Sua postura competitiva é de diferenciação, com forte orientação ao cliente, ao oferecer diversidade e flexibilidade de portfólio, qualidade e customização de produtos. Diversas alianças são estabelecidas na medida em que são fundamentais à implementação desta postura, com vistas principalmente ao aprofundamento dos relacionamentos. O processo de formulação / implementação estratégico tem evoluído de um paradigma posicionamento para uma visão mais integrativa e tende a ser mais participativo comparado ao passado.

As principais alianças são apresentadas a seguir como resposta à segunda pergunta da metodologia adotada para avaliação estratégica.

\section{Quais são as Alianças Estratégicas da "Ego-rede" da CVRD-UMF?}

A pesquisa revelou que a CVRD-UMF estabelece alianças estratégicas com clientes, concorrentes, fornecedores e complementors, mas não com substitutos e "novos entrantes" (por isso não constam nas Tabelas 1 e 2 e na Figura 1). Como parte da sua estratégia, ela busca parcerias com clientes e fornecedores líderes em seus mercados. Suas alianças são tipicamente bilaterais, havendo algumas multilaterais envolvendo clientes, fornecedores e complementors. Na Tabela 1 apresenta-se um retrato das suas alianças principais.

Note que, na Tabela 1, as alianças que predominam em cada classe de parceiros estão em negrito. As características referem-se genericamente aos relacionamentos típicos ou mais importantes. Destaca-se que, além dos contratos de fornecimento de longo prazo típicos da indústria, as principais alianças da CVRD-UMF com seus clientes são joint ventures. Essas são cada vez mais freqüentes, expressando conexões fortes entre os parceiros, e tendo um escopo que transcende as fronteiras dos seus países. Com relação aos concorrentes, em 2000/2001, a CVRD liderou um processo de consolidação da indústria no Brasil, o que resultou em uma série de aquisições (e.g. Socoimex, Samitri/Samarco, GIIC, Ferteco, CAEMI) que facilitaram o acesso aos clientes, mercados e reservas das empresas envolvidas. Já, no caso dos fornecedores e complementors, as alianças ainda não são muito relevantes, 
ESTRATÉGIA - REDES E ALIANÇAS ESTRATÉGICAS NO BRASIL: CASO CVRD

Tatiana L. Tauhata - T. Diana L. v. A de Macedo-Soares

predominando apenas formas tradicionais de contratos de fornecimento de produtos e serviços e P\&D em conjunto.

\begin{tabular}{|c|c|c|c|}
\hline Parceiros & Tipos de Alianças & Estrutura & Modalidade \\
\hline Clientes & $\begin{array}{l}\text { - Joint Ventures } \\
\text { - Contratos de fornecimento de longo prazo } \\
\text { - Investimento acionário minoritário }\end{array}$ & $\begin{array}{l}\text { - Escopo restrito } \\
\text { - Escopo geográfico } \\
\text { global }\end{array}$ & $\begin{array}{l}\text { - Conexão forte } \\
\text { - Natureza colaborativa }\end{array}$ \\
\hline Fornecedores & $\begin{array}{l}\text { - Contratos de fornecimento de longo prazo } \\
\text { - Contratos fornecimento insumos / serviços } \\
\text { - P\&D em conjunto }\end{array}$ & $\begin{array}{l}\text { - Escopo restrito } \\
\text { - Escopo geográfico } \\
\text { global }\end{array}$ & $\begin{array}{l}\text { - Conexão média } \\
\text { - Natureza colaborativa }\end{array}$ \\
\hline Concorrentes & $\begin{array}{l}\text { - Fusões e aquisições } \\
\text { - Joint ventures }\end{array}$ & $\begin{array}{l}\text { - Escopo amplo } \\
\text { - Escopo geográfico } \\
\text { global }\end{array}$ & $\begin{array}{l}\text { - Conexão fraca } \\
\text { - Natureza oportunística }\end{array}$ \\
\hline Complementors & $\begin{array}{l}\text { - Contratos de fornecimento de longo prazo } \\
\text { - P\&D em conjunto } \\
\text { - Joint ventures }\end{array}$ & $\begin{array}{l}\text { - Escopo restrito } \\
\text { - Escopo geográfico } \\
\text { global }\end{array}$ & $\begin{array}{l}\text { - Conexão média/fraca } \\
\text { - Natureza colaborativa }\end{array}$ \\
\hline
\end{tabular}

\section{Tabela 1: Classificação das Alianças Principais da CVRD-UMF}

A Figura 1 mostra o modelo SNA, ou seja, um mapa da "ego-rede" da CVRD, destacando suas alianças principais. De acordo com o modelo, a CVRD-UMF é representada no centro de sua "ego-rede", onde os atores estratégicos que fazem parte de sua rede de valor se dispõem ao longo de uma elipse. Apenas os atores-parceiros da CVRD-UMF são identificados. As cores e o padrão dos laços representam os diferentes tipos de alianças da empresa. Por exemplo, linhas cheias pretas referem-se às aquisições e aos joint ventures, com seus concorrentes e com seus clientes. Os contratos de longo prazo com os fornecedores estão em cinza claro. As linhas pontilhadas referem-se a acordos entre complementors e rivais, e as linhas cinza escuro a participações acionárias nos clientes. Algumas características genéricas mais relevantes das alianças são mostradas, como o status relativo dos parceiros pelo tamanho do ator, a força do laço pela espessura da seta, e a natureza da conexão pela direção da seta (oportunista tem uma seta para a empresa explorada e a colaborativa tem dois sentidos).

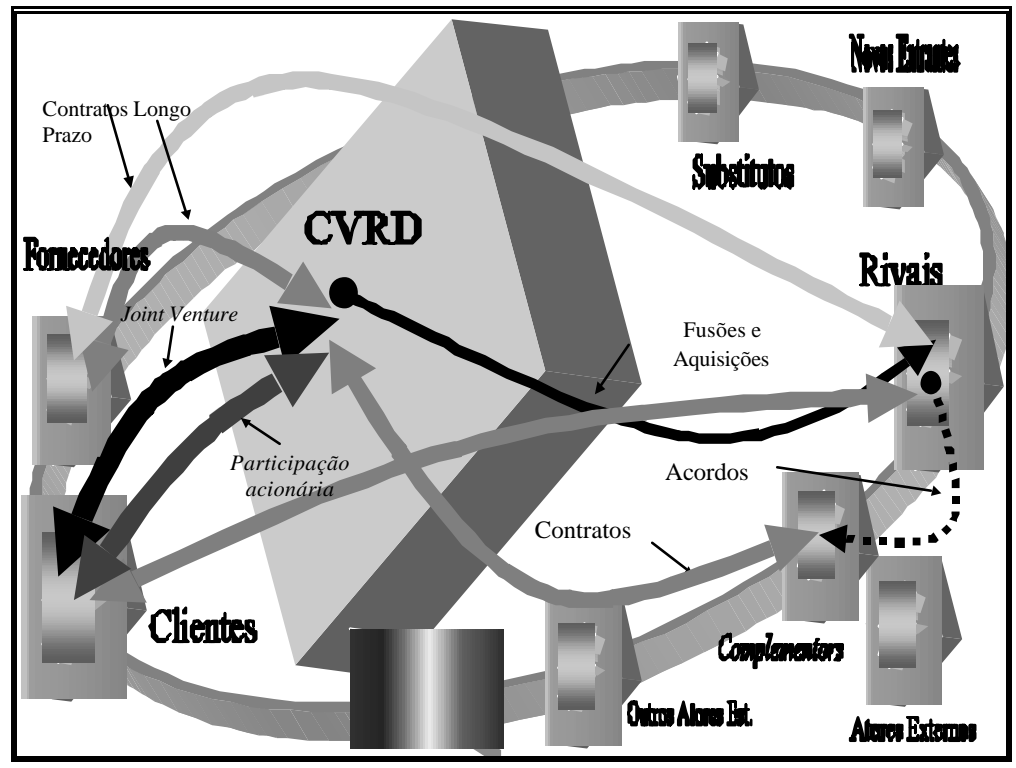


No caso da CVRD-UMF, ratificourse o quanto esta perspectiva relacional é relevante - a maior parte dos respondentes (93\%) ao questionário percebeu a inserção da empresa em redes estratégicas como importante para sua estratégia orientada ao cliente, e considerou que elas estavam mudando a intensidade da competição na indústria. $\mathrm{Na}$ próxima seção detalham-se as implicações das características da "ego-rede" da CVRD.

\section{Quais são as Implicações Estratégicas das Alianças/Redes no Nível da Indústria?}

A Tabela 2 mostra resumidamente as principais implicações estratégicas da "ego-rede" da CVRDUMF, em termos de oportunidades e ameaças, identificadas por meio do confronto de dados pertinentes do levantamento com as listas de referência propostas no ferramental para a análise no nível da indústria.

\begin{tabular}{|l|l|l|}
\hline Dimensões & Construtos / Indicadores & Implicações no Nível da Indústria \\
\hline \multirow{2}{*}{ 1. Estrutura da Rede } & 1.1 Alta densidade & 1.1 Oportunidade \\
\cline { 2 - 3 } & 1.2 Alta centralidade & 1.2 Oportunidade \\
\hline \multirow{2}{*}{ 2. Composição da Rede } & 2.1 Status desfavorável dos clientes & 2.1 Ameaça potencial \\
\hline \multirow{3}{*}{ 3. Modalidade da Rede } & 3.1 Fortes laços & 3.1 Oportunidade \\
\cline { 2 - 3 } & 3.2 Colaborativo & 3.2 Oportunidade \\
\cline { 2 - 3 } & 3.3 Fortes laços entre clientes & 3.3 Ameaça potencial \\
\hline
\end{tabular}

Tabela 2: Implicações Estratégicas da "ego-rede" da CVRD-UMF no Nível da Indústria

Ao examinar os resultados, fica claro que a "ego-rede" da CVRD-UMF cria muito mais oportunidades do que ameaças, devido à sua estrutura, bem como à força das suas conexões. Como maior exportadora de minério de ferro do mundo, ela tem grandes oportunidades ao ocupar uma posição central com relação aos principais países importadores e aos 10 maiores produtores de aço. Embora fosse percebida pelos respondentes como tendo uma posição intermediária frente aos seus rivais, considerando a indústria siderúrgica como um todo e os blocos formados pelos produtores de aço, é vista como podendo tornar essa posição mais central ao estabelecer novas alianças. A força das conexões da sua "ego-rede", também cria oportunidades reais para otimizar seu desempenho ao fortalecer o poder de negociação da empresa com clientes e fornecedores e ao inibir a entrada de novos participantes na indústria. Em realidade, as ameaças são apenas potenciais. Advêm principalmente do fato que as empresas na indústria do cliente estão estabelecendo blocos e redes estratégicas em número e velocidade crescentes.

\section{Quais são as Implicações Estratégicas das Alianças/Redes no Nível da Empresa?}

Conforme mostra a Tabela 3, no nível da empresa, as características das dimensões referentes à estrutura, à composição e ao tipo de laços da "ego-rede" da CVRD constituem praticamente só forças, ao proporcionar recursos, tais como capital informacional, valiosos para sua estratégia de orientação ao cliente.

É apenas na dimensão de gerenciamento da rede que a CVRD apresenta algumas fraquezas, praticamente todas potenciais. A falta de indicadores pertinentes ao desempenho das alianças é a única fraqueza real. Cabe observar que este fato está coerente com a pesquisa de Tavares (2002) que constatou que a minoria das empresas líderes no Brazil utiliza-se de indicadores de desempenho - aliás apenas financeiros - para medir a contribuição das suas alianças e redes ao desempenho global da 
empresa.

\begin{tabular}{|c|c|c|}
\hline Dimensões & Construtos / Indicadores & Implicações no Nível da Indústria \\
\hline \multirow[t]{4}{*}{ 1. Estrutura da Rede } & 1.1 Alta densidade & 1.1 Força \\
\hline & 1.2 Acesso a Recursos & 1.2 Força \\
\hline & 1.3 Padrão Único de Relacionamentos & 1.3 Força \\
\hline & 1.4 Posição Central & 1.4 Força Potencial \\
\hline \multirow[t]{2}{*}{ 2. Composição da Rede } & 2.1 Identidade e alto status dos parceiros & 2.1 Força real e potencial \\
\hline & 2.2 Acesso Satisfatório aos recursos dos parceiros & 2.2 Força \\
\hline \multirow[t]{2}{*}{ 3. Modalidade da Rede } & 3.1 Fortes laços com clientes & 3.1 Força \\
\hline & 3.2 Alianças Colaborativas com clientes & 3.2 Força \\
\hline \multirow[t]{8}{*}{ 4. Gerenciamento da Rede } & $\begin{array}{l}\text { 4.1 Processos de alinhamento estratégico de alianças em } \\
\text { desenvolvimento }\end{array}$ & 4.1 Fraqueza potencial \\
\hline & 4.2 Mecanismos de Governança & 4.2 Força \\
\hline & 4.3 Falta de medidor de performance de alianças & 4.3 Fraqueza \\
\hline & $\begin{array}{l}\text { 4.4.1 Compatibilidade de estratégias operacionais de } \\
\text { parceiros }\end{array}$ & 4.4.1 Força \\
\hline & $\begin{array}{l}\text { 4.4.2 Compatibilidade de culturas e estilos gerenciais } \\
\text { considerados }\end{array}$ & 4.4.2 Força \\
\hline & $\begin{array}{l}\text { 4.5 Processos de gerenciamento de alianças em } \\
\text { desenvolvimento }\end{array}$ & 4.5 Fraqueza potencial \\
\hline & $\begin{array}{l}\text { 4.6 Processos de gerenciamento de mudança apenas em } \\
\text { desenvolvimento }\end{array}$ & 4.6 Fraqueza potencial \\
\hline & 4.7 Mais de 40 anos de experiência com alianças & 4.7 Força \\
\hline
\end{tabular}

Tabela 3: Implicações Estratégicas da "ego-rede" da CVRD-UMF no Nível da Empresa

\section{Resultados para a Gestão da Companhia}

\section{Existem inconsistências das implicações com a estratégia da empresa?}

Os resultados sugerem fortemente que, dadas suas características de diferenciação por qualidade e por suporte, orientada para o cliente, com ênfase no estabelecimento de alianças estratégicas, a estratégia da CVRD-UMF é adequada, na ótica relacional, na medida em que tem o potencial de capitalizar nos recursos valiosos e difíceis de imitar, proporcionados pela alta densidade e pelo padrão estrutural único de uma rede de relacionamentos composta por parceiros com alto status, recursos complementares e estratégias operacionais compatíveis. Estes recursos, tanto físicos, quanto intangíveis - capital informacional pertinente a clientes reais e potenciais, knowhow tecnológico e mercadológico advindos da posição central da empresa $\mathrm{m}$ rede de fornecedores à indústria siderúrgica e dos fortes laços com clientes e concorrentes, representam forças porquanto permitam explorar as numerosas oportunidades reais de atender melhor o cliente, (e.g. desenvolvimento de produtos taylor-made, fornecimento de serviços de logística e consultoria tecnológica associados para viabilizar expansões e aumentos de capacidade) e de aumentar a lucratividade da empresa. Os recursos em questão também constituem forças na medida em que permitam explorar as oportunidades de estabelecer novas alianças com complementors e fornecedores para aumentar o valor do produto na percepção do cliente, ao incorporar serviços, em busca da satisfação de suas necessidades de forma mais completa. A própria natureza colaborativa dos relacionamentos com os clientes na indústria siderúrgica propicia condições favoráveis para a captação dos recursos, devido à confiança que ela implica, podendo contribuir para a redução das ameaças potenciais criadas pela consolidação das empresas que geralmente resulta em um maior poder de barganha dos seus integrantes.

As fraquezas potenciais identificadas não podem ser consideradas inconsistências que comprometem a 
adequação da estratégia, pois se referem somente ao fato que os necessários processos para a gestão das alianças e gestão de mudanças ainda estejam em desenvolvimento. A esse respeito, é significativo que já existe um processo de formalização da garantia do alinhamento destas com sua estratégia, permitindo direcionar de forma coordenada a alocação dos recursos e as outras ações necessárias ao atingimento dos seus objetivos.

A única fraqueza real identificada, por constituir inconsistência entre um componente essencial à estratégia - o estabelecimento de alianças para auxiliar na implementaç ão de sua postura competitiva e seu sistema de medição de desempenho global, foi a falta neste sistema de indicadores da contribuição das suas alianças a esse desempenho.

Quais são as mudanças necessárias nos fatores relacionais ou organizacionais para melhorar ou criar as condições necessárias à adequação estratégica dinâmica?

$\mathrm{Na}$ aplicação do último passo da metodologia, definiu-se como ponto a ser melhorado, para tornar ainda mais eficaz a implementação da estratégia da CVRD-UMF, a inclusão no seu sistema de medição de desempenho de indicadores pertinentes à performance das alianças e da rede formada por elas. A esse respeito, e em linha com as propostas de Kaplan \& Norton (1996) e de Macedo-Soares \& Ratton (1999), recomenda-se considerar indicadores, não somente financeiros e operacionais, mas, também, de inovação e de satisfação de todos os stakeholders, tanto no sistema global da empresa, quanto no de recompensa das pessoas envolvidas nestes relacionamentos estratégicos, de modo a motivar a adoção de práticas-chave para seu gerenciamento bem sucedido. Quanto ao último passo da metodologia, concluiu-se que não há necessidade de alteração na estratégia. A seguir, discutem-se alguns resultados relevantes.

\section{DISCUSSÃO}

\section{Confronto Análises Tradicional e Rela cional}

Nesta seção, os resultados da análise estratégica na ótica "tradicional" são comparados com os da análise na ótica relacional visando destacar a contribuição desta última para a gestão estratégica da empresa. A Tabela 4 apresenta um resumo das implicações estratégicas, limitadas ao nível da indústria, mais significativas para o planejamento estratégico da CVRD-UMF, identificadas na análise tradicional, comparando-as com as implicações destacadas pela análise relacional.

$\mathrm{Na}$ confrontação dos resultados dos dois tipos de análise, fica evidente a contribuição da ótica relacional. Por meio desta, descobre-se que várias ameaças identificadas na análise tradicional podem ser atenuadas por oportunidades criadas pela rede, ou então reforçadas por novas ameaças, e vice- versa. A seguir, comentam-se exemplos mostrados na Tabela 4.

Conforme pode ser visto no item (1), a ameaça de novos entrantes na indústria do minério de ferro (e.g. grandes mineradoras como a Anglo American) pode ser atenuada pelo estabelecimento de laços com os demais participantes da indústria, como no caso das joint ventures com clientes (e.g. a MSG com siderúrgicas japonesas). 
ESTRATÉGIA - REDES E ALIANÇAS ESTRATÉGICAS NO BRASIL: CASO CVRD

Tatiana L. Tauhata - T. Diana L. v. A de Macedo-Soares

\begin{tabular}{|c|c|}
\hline Análise Tradicional & Análise Relacional \\
\hline 1. Ameaça potencial de "novos entrantes" & $\begin{array}{l}\text { 1. Oportunidade real pela alta densidade de laços com } \\
\text { parceiros na indústria, que elevam as barreiras de } \\
\text { entrada }\end{array}$ \\
\hline $\begin{array}{l}\text { 2. Ameaça potencial de redução de market share da } \\
\text { CVRD pelo deslocamento geográfico da produção do } \\
\text { aço para regiões onde é menos competitiva }\end{array}$ & $\begin{array}{l}\text { 2. Oportunidade real pelo estabelecimento de fortes } \\
\text { alianças com clientes }\end{array}$ \\
\hline $\begin{array}{l}\text { 3. Oportunidade real pela consolidação da oferta dos } \\
\text { fornecedores de minério ao aumentar seu poder de } \\
\text { negociação frente a seus clientes siderúrgicos }\end{array}$ & $\begin{array}{l}\text { 3. Ameaça potencial à lucratividade da indústria do } \\
\text { minério de ferro devido à situação competitiva e } \\
\text { financeira vulnerável dos clientes }\end{array}$ \\
\hline $\begin{array}{l}\text { 4. Oportunidade real pelo elevado crescimento da } \\
\text { demanda de aço na China }\end{array}$ & $\begin{array}{l}\text { 4. Ameaça real pela formação de alianças estraté-gicas } \\
\text { dos clientes com os concorrentes da CVRD }\end{array}$ \\
\hline $\begin{array}{l}\text { 5. Ameaça potencial pela consolidação da indústria } \\
\text { siderúrgica com a formação de blocos estratégicos } \\
\text { globais que aumenta seu poder frente aos produtores de } \\
\text { minério. }\end{array}$ & $\begin{array}{l}\text { 5. Oportunidade real pelo estabelecimento de laços da } \\
\text { CVRD com membros dos grupos e blocos que servem } \\
\text { de "porta de entrada" para alianças }\end{array}$ \\
\hline $\begin{array}{l}\text { 6. Ameaça potencial pelo aumento da demanda por } \\
\text { minério de qualidade inferior }\end{array}$ & $\begin{array}{l}\text { 6. Ameaça potencial de alianças com concorrentes } \\
\text { para desenvolver novas tecnologias para aumentar a } \\
\text { competitividade de minérios mais pobres }\end{array}$ \\
\hline $\begin{array}{l}\text { 7. Ameaça potencial pela tendência à redução dos } \\
\text { prazos dos contratos de minério de ferro que aumenta o } \\
\text { risco de perder os clientes }\end{array}$ & $\begin{array}{l}\text { 7. Oportunidade real pela formação de parcerias com } \\
\text { clientes para atender melhor suas expectativas, } \\
\text { aumentando sua satisfação e fidelização. }\end{array}$ \\
\hline $\begin{array}{l}\text { 8. Ameaça potencial pelo fato das reservas de minério } \\
\text { serem abundantes, contribuindo para tendência à super- } \\
\text { oferta } \\
\text { 8. Oportunidade real pelo aumento da demanda de } \\
\text { minério da Coréia do Sul que aumenta as vendas }\end{array}$ & $\begin{array}{l}\text { 8. Oportunidade potencial pelas alianças com } \\
\text { concorrentes que permitem antecipar suas reações } \\
\text { 8. Ameaça real na formação de alianças dos } \\
\text { concorrentes com os clientes }\end{array}$ \\
\hline
\end{tabular}

No item (2) também se tem uma ameaça - esta vez decorrente do deslocamento da produção para a Ásia, onde a CVRD é menos competitiva - atenuada por uma oportunidade, a de formar joint ventures com clientes (e.g. Baovale) que criam fortes laços resultando em retornos superiores devido ao acesso a mais informação e recursos que as demais empresas. Em ambientes onde a quantidade de informação é escassa, os novos entrantes podem ser excluídos caso não tenham estabelecido experiências e redes de contato com as comunidades locais. No sudeste da Ásia, por exemplo, a rápida tomada de decisão e o controle do acesso à informação, por meio da rede de contatos e conexões locais, constituem fontes de vantagem competitiva para as redes chinesas, permitindo que elas capturem as maiores oportunidades de negócio (Haley \& Haley, 1998; Haley \& Tan, 1996).

Por sua vez, os itens 3 e 4 referem-se a oportunidades inibidas por ameaças. No item 4 , a oportunidade de aumento da demanda da China perde parte de sua significância quando seu principal concorrente (Rio Tinto) também estabelece vínculos de longo prazo (e.g. joint ventures "Eastern Ridges" com a Baosteel, comprometendo o market share da CVRD). Haley \& Haley (1998) apontam que nesta região, grupos empresariais locais criam tipos específicos de redes sociais compostas por membros da família, amigos e pessoas de confiança que dominam e influenciam os negócios e o ambiente competitivo.

A indústria do minério tem uma ameaça importante que é, conforme mencionado no item (5), a consolidação da indústria siderúrgica, com a formação de blocos/grupos (e.g. a mega-empresa Arcelor), que resulta no aumento do poder de barganha relativo dos clientes. Esta ameaça pode ser minimizada pela oportunidade de estabelecer laços fortes entre os participantes, tais como as aquisições, ou laços diretos e indiretos com membros dos blocos que podem servir de "porta de 


\section{ESTRATÉGIA - REDES E ALIANÇAS ESTRATÉGICAS NO BRASIL: CASO CVRD}

Tatiana L. Tauhata - T. Diana L. v. A de Macedo-Soares

entrada" para um relacionamento mais abrangente (e.g. participações acionárias em siderúrgicas brasileiras das quais a própria Arcelor participa).

No item (6) apresenta-se um exemplo de ameaça criada pela demanda crescente por minério de qualidade inferior e reforçada por uma ameaça da rede: a formação de alianças para tornar este minério mais competitivo (e.g. projeto Hismelt, na Austrália, envolvendo a Rio Tinto - maior concorrente da CVRD, e Nucor - maior produtor de aço dos EUA).

O item (8) ilustra uma situação ainda mais complexa. Uma ameaça potencial é ao mesmo tempo atenuada por uma oportunidade e reforçada por uma ameaça que inibe uma outra oportunidade. A abundância das reservas de minério de ferro é uma ameaça potencial no sentido de contribuir para a oferta "confortável" no mercado e para a conseqüente perda de competitividade. As alianças com os concorrentes podem constituir uma oportunidade de atenuar essa perda ao permitir conhecer suas decisões e antecipar suas reações. Por outro lado, a formação de alianças dos concorrentes com os clientes (e.g. joint venture da BHP-Billiton com POSCO) potencializa a ameaça de aumento de oferta adicional, pois implica compromissos de longo prazo de compra e a garantia de market share para esta capacidade adicional do concorrente. Esta mesma ameaça pode comprometer a oportunidade real criada pelo aumento da demanda de minério importado da Coréia do Sul, já que as associações tornam praticamente cativos os potenciais clientes (a POSCO é a maior siderúrgica da Coréia do Sul).

Na pesquisa o mesmo tipo de confronto e análise foi desenvolvido no nível da empresa, em termos de cruzamento de forças e fraquezas (vide Tauhata, 2002); não é apresentado neste artigo apenas por razões de simplificação.

\section{Propostas para a Gestão Estratégica da Empresa}

Por meio destes exemplos, evidenciou-se que a análise das implicações das alianças e redes de relacionamento, mesmo limitada aqui à de oportunidades e ameaças, permitiu revelar aspectos relacionais significativos para o planejamento estratégico da empresa em estudo. Ao mesmo tempo, ficou claro que é fundamental complementar e confrontar os resultados obtidos pela análise relacional com os da tradicional.

Destacam-se algumas implicações para a tomada de decisão estratégica da CVRD:

(i) os resultados mostram que a participação da empresa em alianças e redes estratégicas deve ser vista de um modo integrado, no contexto da indústria, dos fatores nacro-ambientais, da rede de valor da empresa, e de seus recursos / competências e condições organizacionais;

(ii) as implicações evidenciam que a formação de alianças e redes estratégicas constituem uma alternativa mais adequada às formas usuais de contratos de fornecimento de longo prazo, em particular com clientes, pois contribuem para fortalecer o relacionamento com os clientes, aumentar o valor percebido dos produtos e serviços ofertados, atenuar a ameaça do aumento de poder dos clientes com a consolidação da indústria siderúrgica e contribuir para sua vantagem competitiva. Em alguns casos, as redes podem contribuir para manter um ambiente que protege as competências centrais e a vantagem competitiva das empresas (Haley, 1997, p. 592);

(iii) dado que as alianças com complementors ainda não são significativas, é recomendável identificar aqueles que possam ser bons parceiros de alianças futuras cruzando com recursos / competências complementares de que a CVRD ainda necessite para satisfazer seus clientes de forma mais plena. 


\section{ESTRATÉGIA - REDES E ALIANÇAS ESTRATÉGICAS NO BRASIL: CASO CVRD \\ Tatiana L. Tauhata - T. Diana L. v. A de Macedo-Soares}

(v) as alianças e redes já constituídas devem ser mapeadas com mais detalhes no sentido de identificar os atores (e não apenas seus papéis genéricos) e exploradas de modo a aumentar o capital social e informacional capturado pela CVRD, alavancando-se por meio dos laços diretos e indiretos com seus parceiros e outros atores de sua arena competitiva;

(vi) os processos de gestão das alianças e de mudanças devem ser desenvolvidos: os gerentes devem aprender a reconhecer a evolução dos relacionamentos (Haley \& Tan, 1996), gerenciar os conflitos que eventualmente ocorram e compreender o papel institucional e de desenvolvimento das redes nos seus mercados (Haley \& Haley, 1998);

(vii) para reforçar a sua atuação neste contexto de redes, deve ser feita uma análise prospectiva mais aprofundada dos clientes. Sugere-se identificar aqueles que devem ser perseguidos como parceiros de novas alianças para se aproveitar dos chamados efeitos "lock-in" (isto é, de "aprisionamento" do parceiro) que acontecem nas redes. Os clientes que apresentam ameaças também devem ser identificados para evitar que relacionamentos muito estreitos privem a CVRD de oportunidades futuras;

(viii) paralelamente, é fundamental uma compreensão aprofundada das implicações estratégicas das redes de relacionamento na indústria de seus clientes - a siderurgia - em processo de restruturação, de forma a sustentar sua vantagem competitiva neste novo cenário.

Com base nesta avaliação, concluiu-se que para a proposta, avaliação e implementação de estratégias de empresas que atuam em alianças e redes estratégicas, como é o caso da CVRD, a ótica relacional contribui com subsídios valiosos que não poderiam ser contemplados por meio de análises estratégicas tradicionais. A seguir, fazem-se algumas considerações finais e recomendações para futuras pesquisas.

\section{CONCLUSÕES E RECOMENDAÇÕES}

O estudo de caso das alianças e redes da CVRD-UMF com o auxílio do ferramental de Macedo-Soares (2002) pode revelar novas contribuições gerenciais para a administração de empresas em um contexto dinâmico globalizado tais como o da CVRD. Permitiu identificar as implicações estratégicas das principais alianças / redes de relacionamento para a unidade sob estudo, e mostrou a relevância de um ferramental prático para a avaliação da adequação estratégica de empresas que atuam em alianças e redes estratégicas. Vale mencionar que a grande maioria dos executivos (93\%) da CVRD-UMF disse explicitamente que um ferramental para análise e gestão estratégica pela ótica relacional poderia contribuir de forma significativa para seu planejamento estratégico.

No caso da CVRD, bem como de outras empresas brasileiras e multinacionais que buscam expandir suas operações, a pesquisa evidenciou o quanto a formação e gestão de redes/alianças podem ser componentes críticos para o sucesso de suas estratégias, fortalecendo seus relacionamentos com os vários atores estratégicos que compõem sua rede de valor, alavancando-os como fonte de informação sobre oportunidades e ameaças, acelerando a tomada de decisão e reduzindo as barreiras à entrada em outros mercados.

Verificou-se que a perspectiva relacional agrega novos elementos para a tomada de decisão estratégica a respeito das oportunidades e ameaças, forças e fraquezas, tanto reais quanto potenciais, que não poderiam ser detectadas pela simples análise dos fatores organizacionais, estruturais da indústria e macro-ambientais interagentes. Constatourse também que ameaças podem ser atenuadas ou anuladas por oportunidades, ou até mesmo reforçadas por novas ameaças constituídas pela redes identificadas com a visão relacional, e vice-versa. 


\section{ESTRATÉGIA - REDES E ALIANÇAS ESTRATÉGICAS NO BRASIL: CASO CVRD \\ Tatiana L. Tauhata - T. Diana L. v. A de Macedo-Soares}

Ao mesmo tempo em que proporcionou estas lições valiosas para outras empresas, o estudo na CVRD abriu novos horizontes de pesquisa ao confirmar a importância de expandir a análise além da "egorede" da empresa apesar das dificuldades de fazê-lo (Galaskiewicz \& Zaheer 1999; Nohria \& Garcia Pont 1991, Troccoli \& Macedo-Soares, 2002).

Como exemplo ilustrativo do ponto acima mencionado, a Figura 2 mostra a complexidade de se considerar alguns relacionamentos que estabelecem conexões entre as "ego-redes" de parceiros de alianças, no caso particular da CVRD e da Baosteel, seu principal parceiro na China. As diversas alianças entre os participantes configuram a teia de relações entre os vários atores de suas respectivas redes de valor: a CVRD e seus clientes - siderúrgicas brasileiras e chinesas - e seus concorrentes, que são ao mesmo tempo, concorrentes da Baosteel, e seus fornecedores de minério. Estes relacionamentos tornam mais complexas as transações entre os participantes, e provocam a evolução da "ego-rede" da empresa focal em direção a um conjunto de "ego-redes" e, no limite, à rede total, que seria o conjunto das "ego-redes" de todos os atores.

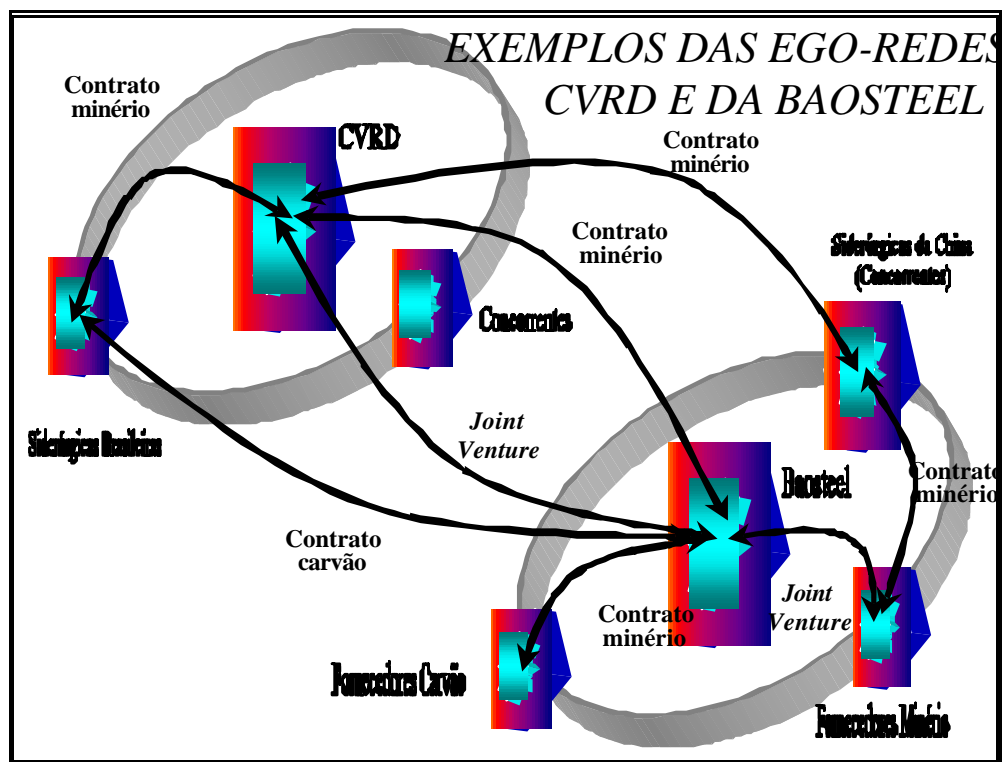

Figura 2: Seção das "Ego-Redes" da CVRD e da Baosteel

Como conclusão, sugere-se que este trabalho sirva como motivação para futuras pesquisas acadêmicas na área, em particular no Brasil, onde existem por enquanto poucos estudos sobre redes sob a perspectiva estratégica. Como sugestões para novas pesquisas, pode-se citar: investigar um contexto mais abrangente de alianças/redes, visando identificar a rede total da CVRD e de seus parceiros diretos; refinamento do ferramental de Macedo-Soares adaptando e aplicando o modelo a diferentes tipos de indústrias e complementando-o com novos construtos e indicadores relacionais alternativos; expandir o escopo da análise estratégica incorporando elementos que reflitam as implicações da rede total.

Adicionalmente, considerando-se o caráter global crescente das redes, recomenda-se que pesquisadores aprofundem questões relativas à gestão das mudanças estratégicas nas redes de empresas globalizadas, explorando a riqueza da complementaridade das suas culturas para suas respectivas vantagens competitivas, bem como os diferentes estilos e práticas de gestão e de tomada de decisão estratégica.

\section{Artigo recebido em 30.01.2003. Aprovado em 15.11.2003}


ESTRATÉGIA - REDES E ALIANÇAS ESTRATÉGICAS NO BRASIL: CASO CVRD

Tatiana L. Tauhata - T. Diana L. v. A de Macedo-Soares

\section{REFERÊNCIAS BIBLIOGRÁFICAS}

ANAND, B. N.; KHANNA T. Do Firms Learn to Create Value? The Case of Alliances. Strategic Management Journal, v. 21, Special Issue, p. 295-316, 2000.

AUSTIN, J. E. Managing in Developing Countries: Strategic Analysis and Operating Techniques, New York: The Free Press, 1990.

BARNEY, J. B. Firm resources and sustained competitive advantage. Journal of Management, v. 17, p. 99-102, 1991.

BARNEY, J. B. Gaining and Sustaining Competitive Advantage. Ohio: Addison -Wesley Publishing Company, 1996.

BRANDENBURGER, A.M.; NALEBUFF, B.J. Co-opetition. New York: Doubleday. 1997.

COLliS, D. J.; MONTGOMERY, C. A. Creating Corporate Advantage. Harvard Business Review. May-June 1998, p. 71-83.

CONTRACTOR, N., WASSERMAN S.; FAUST, K. Testing multi-level, multi theoretical hypotheses about networks in $21^{\text {st }}$ century organizational forms: An analytic framework and empirical example. Paper presented at International Communication Association Meeting, Acapulco, Mexico, 2000.

DELOITTE TOUCHE TOHMATSU (2002). As empresas que mais crescem no Brasil. Rio de Janeiro: Deloitte, 2002.

DE PAULA, G. Mudanças Patrimoniais na Indústria de Minério de Ferro e seus Impactos na Competitividade da Siderurgia Brasileira. Texto para Discussão, Uberlândia, Instituto de Economia da Universidade Federal de Uberlândia, 2000a.

DE PAULA, G. Consolidação da Siderurgia Mundial. Metalurgia \& Materiais, p. 260-264, 2000b.

DOUMA, MARC V., BILDERBEEK JAN, IDENBURG, PETER J. \& LOOISE, JAN KEES. Strategic Alliances: Managing the Dynamics of Fit. Long Range Planning, v. 33, p. 579-598, 2000

DYER, J. H.; SINGH, H. The Relational View: Cooperative Strategy and Sources of Interorganizational Competitive Advantage, Academy of Management Review, v. 23, n. 4, p. 660680, 1998.

FAHEY, LIAM; RANDALL, R. M. Learning from the Future - Competitive Foresight Scenarios. New York: John Willey \& Sons, Inc., p. 22-38, 1998.

GALASKIEWICZ, J.; ZAHEER, A. Networks of Competitive Advantage. Research in the Sociology of Organizations, Jai Press Inc., v. 16, p. 237-261, 1999.

GULATI, R. Alliances and Networks. Strategic Management Journal, v. 19, p. 293-317, 1998.

GULATI, R.; NOHRIA, N.; ZAHEER, A. Strategic Networks. Strategic Management Journal, v. 21, p. 203-215, 2000. 
ESTRATÉGIA - REDES E ALIANÇAS ESTRATÉGICAS NO BRASIL: CASO CVRD

Tatiana L. Tauhata - T. Diana L. v. A de Macedo-Soares

GNYAWALI, DEVI R. \& MADHAVAN, RAVINDRANATH, Cooperative networks and competitive dynamics: a structural embeddedness perspective. Academy of Management Review, v. 26, n. 3, p. 431-445, 2001.

HALEY, G. T. A Strategic Perspective on Overseas Chinese Networks' Decision Making. Management Decision, v.. 35, n. 8, p. 587-94, 1997.

HALEY, G. T. ; HALEY, U. C. V. Boxing with Shadows: Competing Effectively with the Overseas Chinese and Overseas Indian Business Networks in the Asian Arena. Journal of Organizational Change Management, v.. 11, n. 4, p. 301-320, 1998.

HALEY, G. T.; TAN, C.-T. The Black Hole of South-East Asia: Strategic Decision Making in an Informational Void. Management Decision, v. 34, n. 9, p. 37-48, 1996.

HOFER, C.; SCHENDEL D. E. Strategy Formulation: Analytical Concepts, St. Paul MN, 1978.

KALE P.; SINGH H.; PERLMUTTER, H.. Learning and Protection of Proprietary Assets in Strategic Alliances: Building Relational Capital, Strategic Management Journal, v. 21, p. 217-237, 2000.

KAPLAN, R. S.; NORTON, D. P. Using the Balanced Scorecard as a Strategic Management System. Harvard Business Review, January-February, p. 75-85, 1996.

KNOKE, D. Changing Organizations - Business Networks in the New Political Economy. Westview. 2001.

KOTHA, SURESH; VADLAMANI, BHATT L. Assessing Generic Strategies: An Empirical Investigation of Two Competing Typologies in Discrete Manufacturing Industries. Strategic Management Journal, v. 16, n. 1, p. 75-83, 1995.

MACEDO-SOARES, T. D. L. v. A. Strategic alliances and networks: conceptual tools for strategic assessments, Proceedings of GBATA International Conference 2002, Rome, St. John's University, p. 292-305, 2002.

MACEDO-SOARES, T.D. L.v.A.; Ratton, C. A. Medição de Desempenho e Estratégias Orientadas para o Cliente: Resultado de uma Pesquisa de Empresas Líderes no Brasil. Revista de Administração de Empresas, outubro/dezembro, v. 39, n. 4, p. 46-59, 1999.

MACEDO-SOARES, T.D. L.v.A.; Tauhata, T. L. Ferramental para Análise Estratégica pela Ótica Relacional: Resultados do seu Teste Piloto na Companhia Vale do Rio Doce (CVRD). Salvador, CD ROM do XXVI ENANPAD, Seção "Estratégia em Organizações", 2002.

MINTZBERG, H. Generic Strategies: Toward a Comprehensive Framework. Advances in Strategic Management. JAI Press Inc, v. 5, p. 1-67, 1988.

MORSE, J. M. (Ed.) Critical Issues in Qualitative Research Methods. London: Sage, 1994

NEVES, RENATO (Presidente Rio Doce Asia). "How CVRD Can Contribute to the Growth of the Chinese Steel Industry". 2nd International China Steel \& Raw Materials Conference, Metal Bulletin, Shanghai, China, November 2001.

NOHRIA, N.; GARCIA-PONT, C. Global Strategic Linkages and Industry Structure, Strategic 
Management Journal, v. 12, p. 105-124, 1991.

OJODE, LUCY AKUMU. "A Resource-based View of Strategic Alliances: Organizational Capabilities, Governance, and Performance". Dissertação de Doutorado em Administração, Universidade de Illinois em Urbana-Champaign, 2000.

PITASSI, C.; MACEDO-SOARES, T.D.L.v.A. Redes Estratégicas Virtuais: Resultados Preliminares de um Estudo Exploratório. Salvador, CD ROM do XXVI ENANPAD, Seção "Administração da Informação", 2002.

PORTER, M. Competitive Strategy, New York: The Free Press, 1980.

REA, L. M.; PARKER, R. A. Metodologia de Pesquisa - do Planejamento à Execução. São Paulo: Pioneira, 2000.

RUMELT, R. P. Towards a strategic theory of the firm. In R. B. Lamb (Ed.), Competitive strategic management, p. 556-571. Englewood Cliffs, NJ: Prentice-Hall, 1984.

TAVARES, M. Alianças e redes estratégicas: as tendências nas empresas líderes no Brasil. Dissertação de Mestrado, Pontifícia Universidade Católica do Rio de Janeiro, Departamento de Administração/IAG, 2002.

TAUHATA, T. L. Implicações Estratégicas das Redes de Relacionamento: Estudo de Caso da CVRD. Dissertação de Mestrado, Pontifícia Universidade Católica do Rio de Janeiro, Departamento de Administração/IAG, 2002.

TEX REPORT. "Mining Area C Project of BHP-Billiton”. 10/04/2002.

TEX REPORT. "Rio Tinto to Begin Construction of HIsmelt Plant in Fourth Quarter of 2002". $26 / 04 / 2002$.

TROCCOLI, I. R.; MACEDO-SOARES, T.D. L.v.A. Gestão de Empresas em Grupos Estratégicos: Os blocos de relacionamentos estratégicos. RAUSP (no prelo).

YIN, R. K. Case Study Research - Design and Methods. Londres: SAGE Publications, 1994.

WEBER, R. P. Basic Content Analysis. Newbury Park, CA: Sage Publications, 1990.

WERNERFELT, B. A. A Resource-based View of the Firm. Strategic Management Journal, v. 5, n. 2 , p. 171-180, 1984.

ZAJAC, E. J.; KRAATZ, M. S.; BRESSER, R. K. F. Modeling the dynamics of strategic fit: a normative approach to strategic change, Strategic Management Journal, v. 21, p. 429-453, 2000. 


\section{Apêndice 1 - Coleta de Dados}

\section{COLETA DE DADOS}

Os seguintes métodos foram utilizados para coleta de dados: a) investigação documental - incluindo material disponível eletronicamente, essencialmente aquele de divulgação ao público; b) levantamento das percepções dos gestores e executivos sobre as características da rede estratégica em que a empresa está inserida por meio de um questionário; c) entrevistas com os executivos da unidade em questão, visando checar os pontos levantados no questionário e para o entendimento de questões mais complexas ligadas à gestão da rede estratégica; d) observação participante por parte de um dos autores, que participou da aplicação do ferramental de análise e da observação direta dos resultados, além da condução das entrevistas.

Note que a confidencialidade das informações foi inteiramente respeitada, em todas as circunstâncias, e que qualquer informação apresentada nos resultados obteve autorização prévia expressa da empresa.

No caso do levantamento, o principal instrumento de coleta foi um questionário semi-estruturado para a obtenção de percepções sobre ambiente interno e externo de executivos da empresa, ou seja, com perguntas fechadas e abertas, para obtenção de respostas livres. As perguntas fechadas foram estruturadas de acordo com a Escala Likert 1-5, onde os respondentes deveriam assinalar seu grau de concordância com cada afirmação desde "discordo totalmente" até "concordo totalmente".

O questionário continha 32 questões (sendo que, na maior parte delas, havia espaço livre para comentários dos respondentes). O questionário foi desenvolvido com base nos construtos e indicadores do referencial teórico estabelecido, que foram testados com sucesso por outros autores. Foi elaborado em 4 partes, seguindo as dimensões-chave: (1) Estrutura das Redes/Alianças; (2) Composição das Redes/Alianças; (3) Conteúdo Relacional; (4) Gerenciamento de Redes/Alianças. Embora tenha sido feito um extenso levantamento das alianças existentes (vide Tauhata 2002), as perguntas do questionário eram relativas às alianças e redes de uma forma genérica, sem identificação das alianças e de seus parceiros, referindo-se apenas a seu papel genérico (clientes, fornecedores, concorrentes, etc).

A primeira versão do questionário foi submetida a testes prévios para assegurar sua confiabilidade, fidedignidade e validade, por meio do julgamento de pessoas com certo conhecimento do assunto, para sua formatação final, bem como da realização de um pré-teste com pessoas representativas dos sujeitos pesquisados. O teste do questionário semi-estruturado foi conduzido aplicando-o em outra unidade da companhia, levando a refinamentos no conteúdo e nas instruções de preenchimento. Pretendeu-se com isso assegurar a confiabilidade do instrumento no que concerne às questões estruturadas.

Entre março e maio de 2002, foram enviados e-mails contendo um endereço do site da pesquisa maior na qual o estudo se inseria (www.strategy-research.com) e uma senha individual para acesso ao questionário e preenchimento on-line a todos os empregados envolvidos direta ou indiretamente na tomada de decisão da unidade (num total de 212 pessoas), principalmente gerentes, diretores e assessores. Do total, 54 pessoas responderam, permitindo uma generalização estatística dos resultados para a população alvo com um nível de confiança de $91 \%$ (de acordo com fórmula de Rea \& Parker, 2000).

O questionário não é apresentado neste artigo, em função de seu tamanho, mas pode ser solicitado pelo e-mail redes@strategy-research.com. 
A seguir apresentam-se algumas perguntas, de forma ilustrativa, para entendimento do tipo de pesquisa realizada:

1) Classifique sua concordância com a seguinte afirmação: "A inserção da CVRD em redes de relacionamento é importante para a estratégia de orientação ao cliente da CVRD-MF".

\begin{tabular}{|c|c|c|c|c|c|}
\hline $\begin{array}{c}\text { Não se } \\
\text { Aplica }\end{array}$ & $D C$ & $D$ & $\begin{array}{c}N D \\
N C\end{array}$ & $C$ & $C C$ \\
\hline$\square$ & $\square$ & $\square$ & $\square$ & $\square$ & $\square$ \\
\hline
\end{tabular}

2) Sobre o construto "centralidade"- indicadores: central / intermediária / periférica. "Comparando com seus rivais, classifique a posição de centralidade da CVRD na indústria siderúrgica”

\section{\begin{tabular}{|l|l|l}
$\square$ Central & $\square$ Intermediária & $\square$ Periférica
\end{tabular}}

3) Sobre o construto "escopo geográfico"- indicadores: local / regional / global.

"Quanto ao escopo geográfico, as alianças da CVRD, com cada um de seus parceiros, são":

\begin{tabular}{l|c|c|c|}
\hline \multirow{2}{*}{$\begin{array}{c}\text { Com cada tipo de } \\
\text { parceiro: }\end{array}$} & \multicolumn{3}{|c|}{ Classificação } \\
\cline { 2 - 4 } & Locais & $\square$ & $\square$ Regionais \\
\hline Clientes & $\square$ & $\square$ & $\square$ \\
\hline Fornecedores & $\square$ & $\square$ & $\square$ \\
\hline Concorrentes & $\square$ & $\square$ & $\square$ \\
\hline Complementors & $\square$ & $\square$ & $\square$ \\
\hline
\end{tabular}

4) Como você caracteriza as rotinas e processos de gestão das alianças da CVRD?

\begin{tabular}{|c|c|c|c|c|}
\hline $\begin{array}{c}\text { Processos bem } \\
\text { desenvolvidos }\end{array}$ & $\begin{array}{c}\text { Processos em } \\
\text { desenvolvimento }\end{array}$ & $\begin{array}{c}\text { Iniciativas } \\
\text { informais }\end{array}$ & $\begin{array}{c}\text { Não possui } \\
\text { processos ou } \\
\text { iniciativas }\end{array}$ & $\begin{array}{c}\text { Não sei } \\
\end{array}$ \\
\hline
\end{tabular}




\section{Apêndice 2 - Exemplo de Gráficos de Resultados das Respostas ao Questionário}
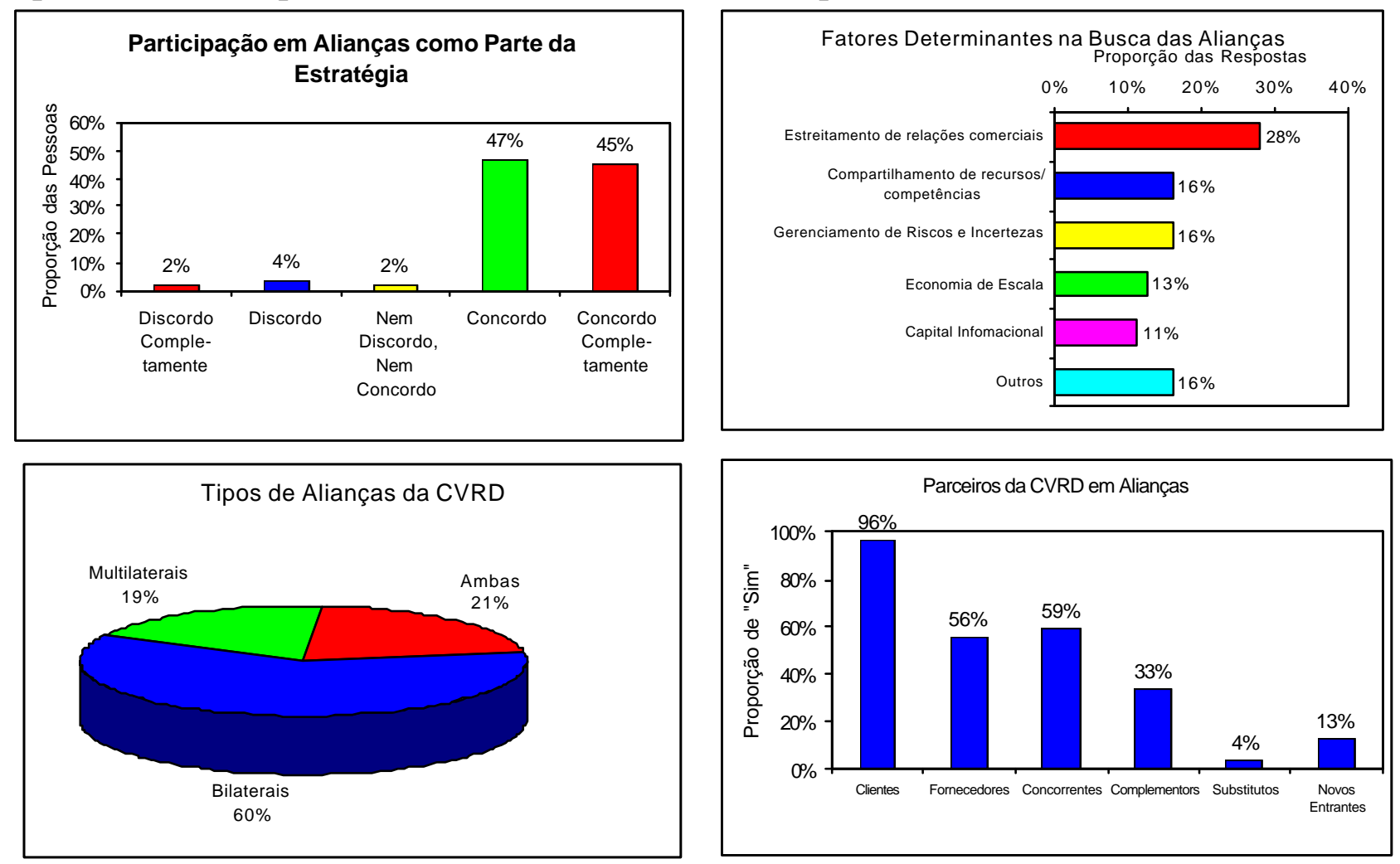

\section{Tatiana L. Tauhata}

E-mail: ttauhata@yahoo.com.br

Endereço: Rua Timóteo da Costa, nº 175- apto 504, Leblon, Rio de Janeiro - RJ, 22.450-130.

Interesses de Pesquisa: Estratégia, Redes e Alianças Estratégicas, Gestão Estratégica.

\section{T. Diana L. v. A. de Macedo-Soares}

Coordenadora de Pesquisa e Professora Associada do Departamento de Administração da PUC-RJ.

E-mail: redes@ @strategy-research.com.br

Endereço: Av. Marquês de São Vicente, no 225 - Gávea, Rio de Janeiro - RJ, 22453-900 